\title{
How to Spare a Life at a Time, Being Mindful of the Red Flags
}

\author{
Catherine Maurice ${ }^{1 \star}$, Kiran Grant ${ }^{2}$ and Austin M. Pereira ${ }^{3}$
}

${ }^{1}$ Department of Medicine, Division of Neurology, Service of Neuro-Oncology, Princess Margaret Cancer Centre, 610 University Avenue, The Gerry and Nancy Pencer Brain Tumor Centre, $18^{\text {th }}$ Floor, University Health Network, University of Toronto, Toronto, Ontario, Canada, M5G 2M9

${ }^{2}$ Faculty of Medicine, University of Toronto, 1 King's College Circle, Medical Sciences Building, Toronto, Ontario, Canada, M5S 1A8

${ }^{3}$ Faculty of Medicine, University of Toronto, 1 King's College Circle, Medical Sciences Building, Toronto, Ontario, Canada, M5S 1A8

\section{*Corresponding author}

Catherine Maurice, Department of Medicine, Division of Neurology, Service of Neuro-Oncology, Princess Margaret Cancer Centre, 610 University Avenue, The Gerry and Nancy Pencer Brain Tumor Centre, $18^{\text {th }}$ Floor, University Health Network, University of Toronto, Toronto, Ontario, Canada, E-mail: Catherine. Maurice@uhn.ca

Submitted: 02 Jan 2020; Accepted: 14 Jan 2020; Published: 22 Jan 2020

\begin{abstract}
In an era dominated by high-yield technology and novel therapies, a clinician's insight and mindful reasoning remain more powerful than fine point instruments. During the course of our medical training, we are taught to consider the most prevalent aetiologies upfront, since "frequent conditions are widespread 》. Moreover, we are trained to develop a unicist vision in front of a clinical scenario, especially when young patients are concerned. However, we shall never forget that the exceptional case will eventually present to clinic. It is our responsibility to recognize the Red Flags. Every patient has only one life, and good clinical awareness protects those lives. The case discussed in this review is highly pertinent for numerous medical fields, mentioning: Neurology, Neurosurgery, Internal Medicine, Psychiatry, Emergency Medicine, Family Medicine, General Surgery and Endocrinology. Numerous specialists are involved in a single case. A gentleman in his early 30 s presents is diagnosed with a low-grade oligodendroglioma involving unilaterally the basal ganglia, documented clinically and radiologically to be stable for years. While he recited his story, we listened carefully. This young man mentioned one sentence, which retrospectively saved his life.
\end{abstract}

Keywords: Oligodendroglioma, Conversion Syndrome, Structural Seizures, Focal Seizure, Tonico-Clonic Generalizred Seizure, Metabolic seizure, Hypoglycemia, Dystonia, Pseudoseizure, Insulinoma.

\section{Introduction}

In medicine, we are trained to consider a common denominator, a "unifying explanation", to account for several concomitant symptoms reported by a single patient. This is particularly relevant in the context of young adults. Individuals presenting underlying neurologic or oncologic conditions are prone to develop further comorbidities and it is more prudent to slightly extend our work-up if a doubt persists. In the particular context of brain tumor patients, no matter the age factor, anyone presenting to a follow-up visit with new neurological symptoms or signs mandates particular attention.

Case Scenario and Discussion

A young patient in his early thirties, diagnosed six years prior with a low-grade glioma, presents to Princess Margaret Cancer Centre for the investigation of new neurological manifestations. More precisely, he presented a new occurrence of paroxysmal hyperkinetic movements involving predominantly the contralateral (right-sided) upper limb, impacting his daily activities and schooling. His glioma was initially diagnosed following an inaugural focal tonic clonic seizure, secondarily generalized. There was no evidence of clinical or radiological progression on the brain MRI since the inaugural presentation. Our young patient certified that he was compliant to his medication, unchanged for years, consisting of phenytoin $300 \mathrm{mg}$ PO OD every other day. There was no recent change in his weight or diet, or potential correlation with the recent use of a natural product of interfering agent. The three clinical pearls below represent a systematic approach. If followed cautiously, those strategic points are more useful than fine point technology to lead to a proper diagnosis.

Clinical Pearl 1: Facing this type of scenario, before reasoning on the likelihood of every potential diagnosis, the key is to determine the nature of the movements described $[1,2]$.

A systematic reasoning process is essential, considering the most plausible aetiologies corresponding to the type of observed movements [Table 1] [3-5]. 
Table 1: Various conditions potentially leading to an "hyperkinetic involvement of a single limb" in specific scenarios. Aetiology example and movement characteristics described for each condition

\begin{tabular}{|l|l|l|}
\hline Movement & Cause Example & Movement Characteristics \\
\hline 1. Seizure & $\begin{array}{l}\text { Non Compliance to } \\
\text { Antiseizure Drugs }\end{array}$ & $\begin{array}{l}\text { Not possible to initiate or stop the stereotyped rhythmic } \\
\text { movement by voluntary control, tongue biting, urinary } \\
\text { incontinence, intubation upon ER arrival. }\end{array}$ \\
\hline 3. Myoclonus & Leptomeningeal seeding/infiltration & $\begin{array}{l}\text { Quick involuntary muscular jerk, of epileptic or non-epileptic } \\
\text { nature. Hypnagogic and hypnopompic timing frequent. }\end{array}$ \\
\hline 4. Chorea Hemiballismus & $\begin{array}{l}\text { Focal contralateral lesion involving basal } \\
\text { ganglia (caudate-subthalamic nucleus) ex. } \\
\text { Tumoral progression, radiation necrosis. }\end{array}$ & $\begin{array}{l}\text { Uncontrollable and usually painful muscular contraction caused } \\
\text { by an aberrant brain signal. }\end{array}$ \\
\hline 5. Tremor & $\begin{array}{l}\text { Essential tremor, more pronounced in a weaker } \\
\text { arrief non-stereotyped random movement, fluid but }\end{array}$ & $\begin{array}{l}\text { Oscillatory (somehow rhythmic) involuntary movement, } \\
\text { muscular contraction/relaxation. }\end{array}$ \\
\hline 6. Cramp & Poor blood circulation & $\begin{array}{l}\text { Muscular contraction, unpredictable and usually painful, } \\
\text { associated for sec-min to a "paralysis-like" effect of the affected } \\
\text { muscle. }\end{array}$ \\
\hline 7. Conversion Syndrome & Anxiety 2 ${ }^{\text {nd } \text { to a specific trigger factor }}$ & $\begin{array}{l}\text { Suggestible, Suppressible, Modulable by suggestion, } \\
\text { Nonrythmic. }\end{array}$ \\
\hline
\end{tabular}

Clinical Pearl 2: Afterwards, the resolution of the case is based on the precise semiology of the movements. Direct observation is key, either in an outpatient basis, via a video taken on a smartphone, or in the Epilepsy Monitoring Unit during a short admission. The goal is to describe the precise nature and timing of the movements; ideally, at the point to visualize them eyes closed.

Clinical Pearl 3: It is crucial to be mindful of the patient's perception. A patient who already experienced a focal seizure in his life, even just for a few seconds before the generalized phase, should be in measure to determine if the current phenomenon is similar, or completely divergent from the previous symptomatology. If epilepsy remains in top of the differential diagnosis, Table 2 describes the systematic reasoning process relative at this specific condition.

Table 2: Systematic approach to investigate seizure recurrence after several years of primary brain tumor stability, like in the case described. Only applicable if the movement described finally corresponds to suspect seizure activity

\begin{tabular}{|c|c|}
\hline Contributing Factors & Specific Examples \\
\hline 1. Neoplastic & $\begin{array}{l}\text { 1. Tumor progression (residual tumor always remained in place) } \\
\text { 2. Evolution of residual tumor towards a higher grade } \\
\text { 3. Satellite site from primary brain tumor in formation } \\
\text { 4. Development of a new primary brain tumor } 2^{\text {nd }} \text { to prior } \\
\text { radiation therapy } \\
\text { 5. Development of a new primary brain tumor in a context of genetic disease }\end{array}$ \\
\hline $\begin{array}{l}\text { 2. Related to previous } \\
\text { treatment received } \\
\text { A) Surgery }\end{array}$ & $\begin{array}{l}\text { A) Former biopsy/minimal resection site (re: basal ganglia location) modified permanently } \\
\text { cerebral architecture at that precise location. Site will always remain prone to seizure development } \\
\text { in threshold lowered by toxic-metabolic trigger factor for example. }\end{array}$ \\
\hline B) Radiotherapy & $\begin{array}{l}\text { B) 1. Delayed radiation necrosis involving peritumoral area, several years later. } \\
\text { 2. Development of brain tumor } 2 \text { nd to the radiation received. } \\
\text { 3. SMART Syndrome }\end{array}$ \\
\hline Chemotherapy (N/A in this case) & $\begin{array}{l}\text { 4. Delayed brain atrophy, modifying cerebral architecture, representing vulnerable area for seizure } \\
\text { onset (if seizure threshold reduced by toxic-metabolic factor for example). }\end{array}$ \\
\hline 3. Related to current antiseizure medication & $\begin{array}{l}\text { 1. Non-compliance } \\
\text { 2. Significant change in weight or diet (proteins) impacting biodistribution } \\
\text { 3. Medical interaction (drug, natural product or diet) } \\
\text { 4. Change for generic formulation, in certain cases patients notice a difference } \\
\text { 5. Metabolic factor changing the metabolism (clearance) of current drug }\end{array}$ \\
\hline $\begin{array}{l}\text { 4. Other factors; impacting by } \\
\text { reducing seizure threshold }\end{array}$ & $\begin{array}{l}\text { 1. Endocrinopathy } \\
\text { 2. Anxiety/Stress reducing seizure } \\
\text { 3. Electrolytic disbalance } \\
\text { 4. Severe fatigue } \\
\text { 5. Active systemic infection }\end{array}$ \\
\hline
\end{tabular}


In our case, the movements were so frequent that it was possible to observe them during the outpatient appointment. The movements were suggestible, as it was possible to trigger them upon command or via a manoeuvre using a vibrating $128 \mathrm{~Hz}$ tuning fork, positioned on the humeroulnar joint. The new movements were also suppressible in specific positions, or in association to concomitant sensory tricks. Most importantly, they were not rhythmic, stereotyped and the patient exerted some voluntary control on them, in a subconscious way. They were fluctuating in frequency, amplitude and pattern of muscular involvement, by opposition to dystonia. It is not a coincidence if the right upper arm, contralateral to the initial tumor, was involved by predilection. Conversion syndromes, our final diagnosis, is often analogous to previous documented structural seizures. The stress at work was a major trigger factor. The movements disappeared eventually in totality with time and the use of an efficient sensory trick: joining both hands [6].

Several months later, he presented for a new onset of episodes, this time extremely similar to the inaugural seizure according to his description. Each episode lasted one or two minutes, accompanied by loss of consciousness, tongue biting and urinary incontinence. Paramedics were involved every episode, transporting the patients to the nearest emergency department. We traced those notes from different networks and ordered the corresponding files. We ignored initially if it was a coincidence that episode took place in restaurants. Concomitant desaturation mandated intubation. After confirming with the patient, seizures always occurred in a postprandial state. This key element became the cornerstone of our investigation, leading to a diagnosis of malignant insulinoma, before the tumor could progress. The insulinoma, despite its high-grade features, was treated successfully with a curative intent $[7,8]$.
Who knew the key to resolve such a complex case would be found in the history, with only further confirmation by accurate technology? This case emphasizes the importance to stay alert in the presence of red flags, and return to the basics, since every patient has one precious life, which we could protect with good insight and mindfulness.

\section{References}

1. Continuum: Lifelong Learning in Neurology (2010) 16.

2. Continuum: Lifelong Learning in Neurology (2013) 19: 571597.

3. Maurice C, Mason W P (2014) Seizure management in patients with gliomas. Expert Review of Neurotherapeutics 14: 367-377.

4. Rudà R, Soffietti R (2015) What is New in the Management of Epilepsy in Gliomas? Current Treatment Options in Neurology 17: 351 .

5. Crociati Meguins L, Rocha da Cruz Adry R A, Da Silva Júnior S C, Pereira CU, Gonçalves de Oliveira J, et al. (2015) Grosstotal resection of temporal low grade gliomas is a critically important factor in achieving seizure-freedom. Arquivos de Neuro-Psiquiatria 73: 924-928.

6. Bell W L, Walczak T S, Shin C, Radtke R A (1997) Painful generalised clonic and tonic-clonic seizures with retained consciousness. J Neurol Neurosurg Psychiatry 63: 792-795.

7. Okabayashi T, Shima Y, Sumiyoshi T, Kozuki A, Ito S, et al. (2013) Diagnosis and management of insulinoma. World J Gastroenterol 19: 829-837.

8. Murakami T, Yamashita T, Yabe D, Masui T, Teramoto Y, et al. (2017) Insulinoma with a History of Epilepsy: Still a Possible Misleading Factor in the Early Diagnosis of Insulinoma. Intern Med 56: 3199-3204.
Copyright: (02020 Catherine Maurice, et al. This is an open-access article distributed under the terms of the Creative Commons Attribution License, which permits unrestricted use, distribution, and reproduction in any medium, provided the original author and source are credited. 